Anaesthesist 2017-66:479-490

DOI 10.1007/s00101-017-0329-x

Online publiziert: 4. Juli 2017

(c) Der/die Autor(en) 2017. Dieser Artikel ist

eine Open-Access-Publikation.

CrossMark

\author{
L. Martin ${ }^{1,2} \cdot$ M. Derwall $\cdot$ C. Thiemermann ${ }^{2} \cdot$ T. Schürholz ${ }^{3}$ \\ ${ }^{1}$ Klinik für Operative Intensivmedizin und Intermediate Care, Uniklinik RWTH Aachen, Aachen, \\ Deutschland \\ ${ }^{2}$ The William Harvey Research Center, Centre for Translational Medicine \& Therapeutics, Queen Mary \\ University London, London, Großbritannien \\ ${ }^{3}$ Klinik und Poliklinik für Anästhesiologie und Intensivtherapie, Universitätsmedizin Rostock, Rostock \\ Deutschland
}

\title{
Herz in der Sepsis
}

\section{Molekulare Mechanismen, Diagnose und Therapie der septischen Kardiomyopathie}

\section{Molekulare Mechanismen der septischen Kardiomyopathie}

Das Überleben septischer Patienten ist klar mit dem Ausmaß des Multiorganversagens assoziiert. Hierbei fällt der komplexen Fehlregulation von Makro- und Mikrozirkulation eine entscheidende Rolle zu, die u. a. auf einem intravasalen Volumenmangel und einer peripheren Vasoplegie basiert [17]. Ältere Untersuchungen (mit insuffizienter Volumenund Katecholamintherapie) postulierten eine globale Ischämie als Ursache für die septische Kardiomyopathie [16, 36]. Dies konnte jedoch durch Arbeiten von Cunnion et al. eindrücklich widerlegt werden: Die Autoren fanden bei Patienten mit septischem Schock nach Katheterisierung des Sinus coronarius einen ähnlichen bis leicht erhöhten koronaren Fluss im Vergleich zu Probanden ohne septischen Schock [18]. Des Weiteren belegen Positronen-Emissions-Tomografie(PET)-Untersuchungen mittels 18FFluordesoxyglucose (FDG) keine globale kardiale Hypoxie während der Sepsis [38], sodass heute davon ausgegangen werden kann, dass eine globale Hypoperfusion und Hypoxie keine Rolle in der septischen Kardiomyopathie spielen. Vielmehr besteht zunehmend Evidenz, dass die abgeschwächte adrenerge Antwort kardiomyozytärer Filamente einen globalen und direkten Mechanismus der septischen Kardiomyopathie darstellt $[95,100]$. Hierfür scheinen suprazelluläre (Abnahme $\beta_{1}$-adrenerger Rezeptoren und Zunahme $\beta_{3}$-adrenerger Rezeptoren) und intrazelluläre (Abnahme stimulierender G-Proteine und Zunahme inhibierender G-Proteine) Mechanismen von entscheidender Bedeutung zu sein [12, 109]. Diese Veränderungen resultieren in einer reduzierten Aktivität der Adenylatzyklase, die mit reduzierten Spiegeln von zyklischem Adenosinmonophosphat (cAMP) einhergeht, das die negativen Ergebnisse der Untersuchung des cAMP-abhängigen Inotropikums Milrinon (Phosphodiesterase-3-Inhibitor) zumindest teilweise erklärt [8].

\section{Zirkulierende Faktoren, Zytokine und Stickstoffmonoxid}

Bereits 1985 beschrieb die Arbeitsgruppe um Parillo, dass das Serum von Patienten mit akutem septischen Schock Faktoren enthält, die die Kontraktionskraft von isolierten Kardiomyozyten vermindert (- Tab. 1; [84]). Dieselbe Arbeitsgruppe konnte 4 Jahre später zeigen, dass ihre Ergebnisse auf dem Vorhandensein von Tumor-Nekrose-Faktor- $\alpha$ (TNFa) beruhten [76]. In folgenden Untersuchungen wurde belegt, dass hierbei auch Interleukin-1 $\beta$ (IL-1 $\beta$ ) eine Rolle spielt [53], und mehrere jüngere Studien postulieren eine Schlüsselrolle für diverse proinflammatorische Zytokine (- Tab. 1) in der Frühphase der septischen Kardiomyopathie [111]. In einer klinischen Observationsstudie untersuchten Landesberg et al. den Zusammenhang zwischen diversen im Serum vorhan- denen pro- und antiinflammatorischen Zytokinen (IL-1 $\beta$, IL-6, IL-8, IL-10, IL18, TNF- $\alpha$ ) und der kardialen Funktion bei 105 Patienten mit schwerer Sepsis und septischem Schock [57]. Überraschenderweise zeigte sich für keines der untersuchten Zytokine eine signifikante Korrelation mit der systolischen oder der diastolischen myokardialen Kontraktilität der Patienten [57]. Aufgrund ihrer relativ kurzen Halbwertszeit nach experimenteller Gabe (zwischen maximal 8 und 48 h) können Zytokine nicht für die prolongierte kardiale Dysfunktion über Tage in der Sepsis verantwortlich sein. Sowohl TNF- $\alpha$ und IL-6 als auch IL- $1 \beta$ induzieren die Freisetzung nachgeschalteter Faktoren in der Kaskade proinflammatorischer Mediatoren (wie z. B. Stickstoffmonoxid oder freie Sauerstoffradikale). Kumar et al. postulierten daher, dass die zuvor gezeigten Effekte diverser Zytokine durch Stickstoffmonoxid (NO) vermittelt werden [54]. In der Tat verhindert die Therapie mit nichtspezifischen NO-Inhibitoren, wie z. B. N-Methyl-L-Arginin oder Methylenblau, eine sepsisassoziierte kardiale Dysfunktion [49, 54], auch wenn das Outcome der Patienten unverändert ist [49]. Die funktionelle Rolle von NO in der septischen Kardiomyopathie ist bis heute nicht vollständig verstanden. Dies liegt zum einen an dem Vorhandensein verschiedener Isoformen der induzierbaren Stickstoffmonoxidsynthasen (iNOS) und deren unterschiedlichen Wirkungsweisen am Herz [47] sowie 


\begin{tabular}{|c|c|c|}
\hline Klassifikation & Zirkulierender Faktor & Referenz \\
\hline Zytokine & $\begin{array}{l}\text { Interleukin (IL-1 } \beta \text {, IL-6) } \\
\text { Tumor-Nekrose-Faktor-a }\end{array}$ & {$[53,64,76]$} \\
\hline Komplementfaktoren & $\mathrm{C} 5 \mathrm{a}$ & [79] \\
\hline $\begin{array}{l}\text { "Pathogen-associated molecular } \\
\text { patterns" (PAMP) }\end{array}$ & $\begin{array}{l}\text { Lipopolysaccharid (LPS), Lipoteichonsäuren } \\
\text { (LTA) }\end{array}$ & {$[6,32]$} \\
\hline $\begin{array}{l}\text { "Damage-associated molecular } \\
\text { patterns" (DAMP) }\end{array}$ & $\begin{array}{l}\text { High-Mobility-Group-Protein B1 (HMGB1) } \\
\text { Histone } \\
\text { Heparansulfat }\end{array}$ & {$[34,46,68]$} \\
\hline Matrixmetalloproteinasen (MMP) & MMP-9 & {$[56]$} \\
\hline
\end{tabular}

zum anderen an der fehlenden Evidenz, ob NO selbst oder dessen Metaboliten (Peroxynitrit) für die zytokinvermittelte kardiomyozytäre Dysfunktion verantwortlich sind [54]. Peroxynitrit, das durch die Reaktion von NO und Superoxidradikalen gebildet wird, führt über eine Dysfunktion der mitochondrialen Atmungskette $\mathrm{zu}$ einer kardiomyozytären Kontraktionseinschränkung [15]. Des Weiteren wurde kürzlich eine mitochondriale NOS identifiziert, die zur septischen Kardiomyopathie durch die vermehrte Produktion von NO und die Öffnung mitochondrialer „permeability transition pores" beiträgt [15]. Auch wenn zunehmende Evidenz darüber besteht, dass NO zu der zytokininduzierten kardiomyozytären Dysfunktion beiträgt, fehlen weitere Studien, die die Rolle der verschiedenen iNOS-Formen sowie die schlussendlichen Zielstrukturen (z. B. Kalziumhaushalt) von NO in Tiermodellen und humanen Studien untersuchen.

\section{Toll-like-Rezeptoren und „pathogen-associated molecular patterns"}

Im Herz exprimieren eine Vielzahl von infiltrierenden Immunzellen sowie die Kardiomyozyten selbst Toll-like-Rezeptoren (TLR) und Zelloberflächenproteine (z. B. CD14), die Wandbestandteile pathogener Mikroorganismen (u. a. Lipopolysaccharide, LPS) sowie endogene "danger molecules“ (s. Abschn. „Endotheliale Dysfunktion und "danger-associated molecular patterns") erkennen $[5,6,9,10,24,27,48,51,77,104]$. Infiltrierende Immunzellen scheinen im Hinblick auf die kardiomyozytäre Kontraktionsstörung v. a. eine indirekte
Rolle einzunehmen, da die Depletion von neutrophilen Granulozyten eine septische Kardiomyopathie im Mausmodell nicht verhindern kann [87]. Vielmehr scheinen infiltrierende Immunzellen über die TLR-vermittelte Produktion proinflammatorischer Zytokine indirekt zur kardiomyozytären Inflammation und Kontraktionsstörung beizutragen [28]. Über eine TLR/MyD88-abhängige Signaltransduktion kommt es zur Aktivierung des nukleären Transkriptionsfaktors NFkB, was in der vermehrten Expression diverser proinflammatorischer Zytokine resultiert. Bis heute sind 9 TLR bekannt, von denen TLR-4 der am besten untersuchte TLR des Herzens ist [111]. Baumgarten et al. konnten eindrücklich zeigen, dass der Knockout von TLR-4 die Abnahme der kardiomyozytären Kontraktilität verhindert [10]. Jüngere Arbeiten beschreiben des Weiteren andere TLR (TLR-2, -5, -9) in der Pathophysiologie der septischen Kardiomyopathie [50, 63, 90]. Neben dem TLR-4 $4^{-/}$verhindert ebenso der TLR- $3^{-/-}$in Mäusen die Progression der septischen Kardiomyopathie [30]. Auch wenn diese und weitere Arbeiten eine klare Evidenz für die kritische Rolle von TLR in der septischen Kardiomyopathie liefern, limitiert die ACCESS-Studie deren klinische Translation. Die Therapie mit Eritoran (einem synthetischen TLR4-Antagonisten) zeigte in dieser Studie keinen Vorteil im 28-Tage-Outcome bei Patienten $(n=1961)$ mit schwerer Sepsis [80]. Pathophysiologisch lassen sich diese (negativen) Ergebnisse u. a. durch die Vielfalt vorhandener „pattern recognition receptors" (wie z. B. TLR-4) erklären, die jeweils unterschiedliche/spezifische Affinitäten zu unterschiedlichen PAMP/ DAMP (s. Abschn. „Endotheliale Dys- funktion und "danger-associated molecular patterns") aufweisen. Nach dem heutigen Wissensstand wundert es daher nicht, dass der undifferenzierte Einsatz eines TLR-4-Antagonisten nicht in der Lage sein konnte, das Outcome von septischen Patienten mit unterschiedlichem Erregerspektrum zu verbessern.

\section{Endotheliale Dysfunktion und „danger-associated molecular patterns"}

Neben Kardiomyozyten sind kardiale Fibroblasten und Endothelzellen maßgeblich an der Pathophysiologie der septischen Kardiomyopathie beteiligt. Kardiale Fibroblasten machen $60-70 \%$ der Gesamtzellzahl im Herz aus und setzen TNF- $\alpha$ sowie MMP-9 während der sepsisassoziierten kardialen Inflammation frei [102]. Im Rahmen der Sepsis kommt es zu einer Vielzahl von pathophysiologischen Mechanismen am Endothel, die zur septischen Kardiomyopathie beitragen [96]. Neben der inadäquaten und heterogenen Verteilung des regionalen Blutflusses (u. a. durch Induktion der endothelialen Stickstoffmonoxidsynthase (eNOS) mit resultierenden erhöhten lokalen NO-Spiegeln) kommt es durch Modulation der endothelialen Glykokalyx zu einer Störung der kapillären Schrankenfunktion [70]. Die Hauptbestandteile dieser endothelialen, luminalen, kohlenhydratreichen Schicht sind negativ geladene Heparansulfatproteoglykane (HSPG), die fortwährend eine dem Umbau unterliegende Diffusionsbarriere für Plasmamoleküle darstellen und somit maßgeblich die vaskuläre Permeabilität regulieren [60].

\section{Heparansulfate}

Die systemische Inflammationsreaktion in der Sepsis wird durch 2 entscheidende Wege induziert und aufrechterhalten: Neben Wandbestandteilen pathogener Mikroorganismen werden endogene "danger molecules" (DAMP) freigesetzt, die im Blut zirkulieren und die systemische Inflammation triggern. $\mathrm{Zu}$ ihnen gehören lösliche Heparansulfate (HS), die von zelloberflächenassoziierten HSPG durch die $\beta$-Endoglykosidase He- 
paranase abgespalten werden und im Blut zirkulieren. Die $\beta$-Endoglykosidase $\mathrm{He}$ paranase ist ein universeller Modulator dieser HSPG und ist neben der Inflammation an Prozessen der Tumorinvasion und Metastasierung beteiligt [70]. Unter dem Einfluss proinflammatorischer Zytokine kommt es durch die Heparanase zu einer Degradation der HSPG $[62,65,110]$. Dies führt zum einen zur Freisetzung zirkulierender proinflammatorischer HS [42, 43] und zum anderen zur sepsisassoziierten mikrovaskulären Permeabilitätsstörung [23]. Neben einer erhöhten Heparanaseaktivität in Lungengeweben von Patienten mit sepsisassoziiertem akuten Lungenversagen [92] konnten Arbeiten unserer Arbeitsgruppe sowohl eine erhöhte Aktivität als auch erhöhte Heparanaselevel im Plasma von Patienten mit septischem Schock aufzeigen [69]. Zudem triggern zirkulierende HS im Blut von Patienten mit septischem Schock maßgeblich die kardiomyozytäre Inflammation [69], da die Stimulation von Kardiomyozyten mit HS zu einem Anstieg des TLR-vermittelten nukleären Transkriptionsfaktors NFkB sowie zur Liberation proinflammatorischer Zytokine führt [69]. Heparansulfatefreies Serum septischer Patienten (HS mittels Affinitätschromatographie und monoklonalem Antikörper entfernt) induziert eine signifikant geringere Inflammation in Kardiomyozyten, verglichen mit unbehandeltem Serum septischer Patienten. Durch Hinzufügen der entfernten HS und Stimulation der Zellen lässt sich die Inflammationsreaktion in ähnlichem Ausmaß wie nach Stimulation mit unbehandeltem Serum reproduzieren [69]. Des Weiteren können HS in vitro eine mitochondriale Dysfunktion in murinen Kardiomyozyten induzieren, die zur Reduktion der metabolischen Reserve führt [22].

\section{Extrazelluläre Histone und High- Mobility-Group-Protein B1}

Neben HS agieren auch Histone als endogene DAMP, die über TLR-2 und TLR$4 \mathrm{zu}$ einer Reduktion des mitochondrialen Membranpotenzials und der zellulären ATP-Spiegel führen [45]. Alhamdi et al. beschreiben, dass zirkulierende

Anaesthesist 2017 - 66:479-490 DOI 10.1007/s00101-017-0329-x

๑ Der/die Autor(en) 2017. Dieser Artikel ist eine Open-Access-Publikation.

\section{Martin · M. Derwall $\cdot$ C. Thiemermann $\cdot$ T. Schürholz}

\section{Herz in der Sepsis. Molekulare Mechanismen, Diagnose und Therapie der septischen Kardiomyopathie}

\section{Zusammenfassung}

Die Bedeutung der septischen Kardiomyopathie wird auch 95 Jahre nach deren Erstbeschreibung im klinischen Alltag noch häufig unterschätzt. Neueste echokardiographische Verfahren belegen eine deutlich unterschätzte Prävalenz bei Patienten im septischen Schock, da sie eine myokardiale Dysfunktion auch bei erhaltener linksventrikulärer Ejektionsfraktion demaskieren. In umfangreicher Forschungsarbeit der letzten Jahre wurden neben systemischen Faktoren diverse komplexe zugrunde liegende molekulare Mechanismen sowie metabolische und strukturelle Veränderungen identifiziert. Diese Erkenntnisse stellen Ansätze für zukünftige, dringend benötigte kausale Therapien dar, um die bis dato zur
Verfügung stehenden supportiven Ansätze zu ergänzen. Die vorliegende Übersichtsarbeit fasst wesentliche aktuelle Aspekte der molekularen Mechanismen der septischen Kardiomyopathie zusammen, stellt aktuelle und zukünftige Strategien in Diagnose und Therapie vor und zeigt die dringliche Notwendigkeit weiterer experimenteller und klinischer Untersuchungen zur Verbesserung der Diagnosestellung sowie zur Identifikation neuer innovativer Therapieansätze in der septischen Kardiomyopathie auf.

\section{Schlüsselwörter}

Sepsis · Kardiomyopathie · Septischer Shock . Kardiale Inflammation · Kalziumhaushalt

\section{Heart in sepsis. Molecular mechanisms, diagnosis and therapy of septic cardiomyopathy}

\section{Abstract}

An impairment of cardiac function is a key feature of cardiovascular failure associated with sepsis; however, its clinical relevance is still underestimated. Recent advancements in echocardiography in patients with septic shock enable a better characterization of septic cardiomyopathy by unmasking a severe, cardiac dysfunction even in the presence of preserved left ventricular ejection fraction. The pathophysiology of septic cardiomyopathy involves a complex mixture of systemic factors and molecular, metabolic, and structural changes of the cardiomyocytes. A better understanding of these factors will enable the discovery of new therapeutic targets for urgently needed disease-modifying therapeutic interventions. To date, the cornerstone of therapeutic management lies in control of the underlying infectious process and hemodynamic stabilization. This review summarizes the pathogenesis, diagnosis, and treatment of septic cardiomyopathy, and highlights the importance of further urgently needed studies aimed at improving diagnosis and treatment for septic cardiomyopathy.

\section{Keywords}

Sepsis - cardiomyopathy · Septic shock . Cardiac inflammation. Calcium metabolism
Histone im Plasma septischer Patienten erhöht vorliegen und mit dem kardialen Troponin T korrelieren. Die Autoren beschreiben des Weiteren, dass hohe Spiegel von Plasmahistonen signifikant mit dem Neuauftreten einer linksventrikulären Dysfunktion sowie mit Arrhythmien assoziiert sind [1]. Dies scheint durch Komplement- (C5a-)vermittelte Neutrophilenaktivierung vermittelt $\mathrm{zu}$ sein, die in der Bildung neutrophiler extrazellulärer Netze (NET) resultiert [46].
Das High-Mobility-Group-Protein B1 (HMGB1) ist ein weiteres kritisches DAMP, das LPS-abhängig von Kardiomyozyten freigesetzt wird. Die HMGB1assoziierte kardiale Dysfunktion wird durch erhöhte Level intrazellulärer reaktiver Sauerstoffspezies (ROS) TLR4-vermittelt induziert. Des Weiteren erhöht HMGB1 TLR-4/ROS-vermittelt den Kalziumausstrom aus dem sarkoplasmatischen Retikulum (SR), was zu einer Abnahme des Kalziumgehalts im SR führt und in einer eingeschränkten 
Kopplung von Erregung und myozytärer Kontraktion resultiert ([114]; s. Abschn. „Kalziumhaushalt und Kardiomyofilamente").

\section{Intrazelluläre molekulare Pathomechanismen}

Neben den beschriebenen suprazellulären Mechanismen kommt es zu einer Vielzahl intrazellulärer Veränderungen in den Kardiomyozyten. Eine kritische Rolle spielen dabei die mitochondriale Dysfunktion sowie eine Dysregulation des Energie- und Kalziumhaushalts, die in den folgenden Abschnitten diskutiert werden.

\section{Mitochondrien und Energie- haushalt}

Derzeit existieren mehrere Theorien zur Rolle der Mitochondrien in der septischen Kardiomyopathie: Neben einer kausalen Beteiligung der Mitochondrien an der Pathophysiologie der septischen Kardiomyopathie postuliert eine andere Theorie ein Epiphänomen. Letztere Theorie vermutet, dass die sepsisassoziierte myokardiale Dysfunktion eine protektive Adaptation an den reduzierten myokardialen Energiestatus während der septischen Kardiomyopathie darstellt, der aus der mitochondrialen Dysfunktion resultiert (vergleichbar zu der Hibernation während der myokardialen Ischämie; [15]). Das Herz ist reich an Mitochondrien, die neben dem Energiehaushalt eine entscheidende Rolle in der Regulierung der Kalziumhomöostase spielen. Als Beispiel hierfür ist der im Rahmen der septischen Kardiomyopathie stattfindende Anstieg der intrazellulären $\mathrm{Ca}^{2+}$-Konzentration zu nennen, der mit einer erhöhten mitochondrialen $\mathrm{Ca}^{2+}$-Konzentration und assoziierter mitochondrialer ROSProduktion einhergeht, die wiederum Komplex V der Atmungskette (ATPSynthase) und auch den Zitratzyklus hemmt [15]. Daher scheint das Ausmaß der mitochondrialen Dysfunktion eine kritische Komponente in der $\mathrm{Pa}$ thophysiologie und der Prognose der septischen Kardiomyopathie darzustellen $[13,61,98]$. Cimolai et al. fassen die Rolle der mitochondrialen Funktion in ihrer Übersichtsarbeit zusammen [15]. Die mitochondriale Dysfunktion scheint, nach initialer Inflammationsreaktion, ein Phänomen der späten Phase der septischen Kardiomyopathie zu sein.

$\mathrm{Zu}$ den Veränderungen der Mitochondrien während der septischen Kardiomyopathie zählen ultrastrukturelle Schäden, die zur Freisetzung mitochondrialer DNA [97] und zur Zunahme der mitochondrialen „permeability transition pore" führen [58]. Die pharmakologische Inhibition der mitochondrialen „permeability transition pore“ mittels Ciclosporinderviaten kann die kardiale Funktion verbessern und die Sterblichkeit im Mausmodell der polymikrobiellen Sepsis reduzieren [58]. In ähnlicher Weise schützt die Gabe von Vitamin E die mitochondrialen Strukturen und Funktionen, was in einer reduzierten Bildung mitochondrialer ROS resultiert und somit die kardiale Funktion in der murinen Sepsis verbessert [112]. Jüngere Untersuchungen zeigen zudem, dass Mitochondrien eine entscheidende Menge an DAMP produzieren (mitochondriale ROS, mitochondriale DNA, ATP und Zytochrom C). Diese Moleküle werden von fragmentierten Mitochondrien in die Zirkulation freigesetzt, triggern die systemische Inflammationsreaktion und führen zu einer Reduktion der Enzymaktivitäten der mitochondrialen Atmungskette sowie der zellulären ATPLevel [15].

Durch die Induktion von „uncoupling proteins“ (UCP) kommt es zu einer Entkopplung der ATP-Synthese vom Sauerstoffverbrauch, die in einer reduzierten Rate an produziertem ATP im Verhältnis zum genutzten Sauerstoff und einem reduzierten Verhältnis von Kreatinphosphat zu ATP resultiert (reduzierte kardiale Effizienz; [11]). Die Bedeutung dieses, unter physiologischen Bedingungen zur Wärmegenerierung und zum Abbau mitochondrialer ROS genutzten, Mechanismus wird im Rahmen der septischen Kardiomyopathie kontrovers diskutiert: Uncoupling protein 2 und 3 scheinen (je nach Zeitpunkt) sowohl protektive Effekte aufzuweisen als auch mit einer reduzierten kardialen Funktion im Rahmen derSepsis assoziiert zu sein $[98,106,116]$.
Mehrere Untersuchungen zeigen des Weiteren eine Zunahme von Auto- und Mitophagie („Qualitätskontrolle zur Elimination defekter Mitochondrien“) im Herz während der Sepsis [15]. Piquereau et al. untersuchten in diesem Zusammenhang die Rolle von Parkin/PARK2, einer Signalkaskade, die maßgeblich an der Ubiquitinierung von Zellorganellen beteiligt ist. Im Vergleich zu Wildtyptieren kam es bei PARK2 $2^{-/-}$-Tieren zu keiner Erholung der kardialen Funktion $48 \mathrm{~h}$ nach LPS-Administration und $\mathrm{zu}$ einer persistierenden, reduzierten Aktivität der oxidativen Phosphorylierung und mitochondrialen Sauerstoffverbrauchsrate. Diese Ergebnisse liefern Hinweise, dass PARK2 und der Mechanismus der Mitophagie für die Erholung der kardialen Funktion von substanzieller Bedeutung sein könnten [86].

\section{Kalziumhaushalt und Kardiomyofilamente}

Die Rolle des Kalziumhaushalts in der septischen Kardiomyopathie wird verdeutlicht, wenn man bedenkt, dass die zuvor beschriebenen Pathomechanismen (Inflammation und mitochondriale Dysfunktion) nur über eine Beeinflussung des intrazellulären Kalziumgehalts oder der myofilamentären Integrität zur kardiomyozytären Kontraktionsstörung beitragen können [37]. Neben der Abnahme der Kalziumsensitivität kardialer Myofilamente durch die vermehrte Phosphorylierung von inhibitorisch wirksamem Troponin-I [66] spielt die Dysfunktion intrazellulärer Kalziumtransporter eine entscheidende Rolle [37]. Hobai et al. fassen die Rolle intrazellulärer Kalziumtransporter in der septischen Kardiomyopathie in ihrer Übersichtsarbeit ausführlich zusammen [37]. Kardiomyozyten, isoliert von septischen Patienten, zeigen in vitro eine Abnahme der Kontraktionsamplitude, die durch die Abnahme der Amplitude intrazellulärer Kalziumströme und durch die Abnahme sarkoplasmatischer Kalziumspiegel begründet ist [7].

Unter physiologischen Bedingungen kommt es während der elektromechanischen Kopplung über L-Typ-Kalziumkanäle zu einem Kalziumeinstrom 


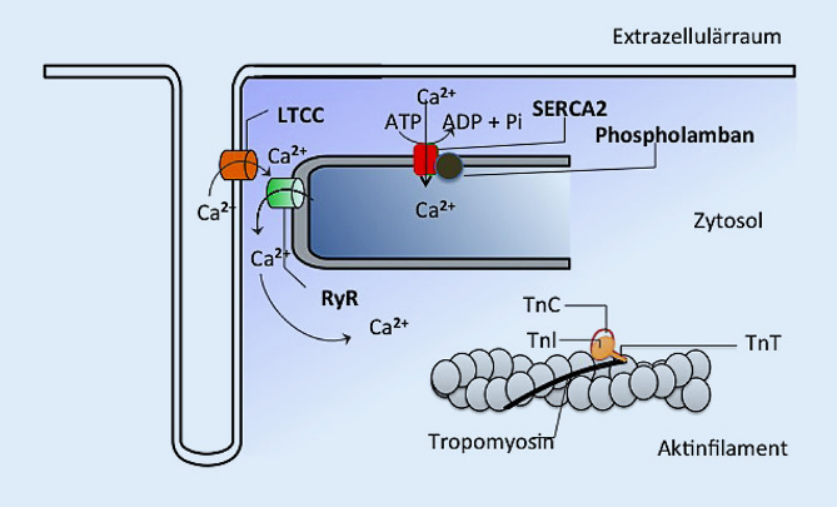

Abb. 1 ATPase des sarkoplasmatischen Retikulums (SERCA2). ADP Adenosindiphosphat, ATP Adenosintriphosphat, $L T$ CCL-Typ-Ca ${ }^{2+}-$ Kanal RyR Ryanodinrezeptor, TnC Troponin C, TnT Troponin T, Tn/Troponin I in die Kardiomyozyten, was ein Freisetzen von Kalzium aus dem SR zur Folge hat. Intrazelluläres Kalzium bindet an Troponin I, das die Bindungsstellen von Aktin und Myosin freigibt und deren Bindung ermöglicht [37]. Am Ende erfolgt die aktive Wiederaufnahme des intrazellulären Kalziums in das SR. Hierfür ist die Kalzium-ATPase des SR (SERCA2) maßgeblich verantwortlich, die über Phospholamban reguliert wird (• Abb. 1). Während der septischen Kardiomyopathie ist die Funktion von SERCA2 inhibiert. Dies resultiert, durch die gestörte Wiederaufnahme von Kalzium in das SR, in einer gestörten diastolischen Relaxation [6]. Auch wenn diese Arbeiten eine kritische Rolle intrazellulärer Kalziumtransporter in der septischen Kardiomyopathie belegen, fehlen bis heute Arbeiten, die die beteiligten Signalwege identifizieren.

\section{Klinik und Diagnosestellung der septischen Kardiomyopathie}

Die septische Kardiomyopathie stellt eine komplexe kardiale Dysfunktion dar, die beide Ventrikel betrifft [3]. Neben unspezifischen Risikofaktoren (Alter, Adipositas) sind bisher keine spezifischen Risikofaktoren bekannt. Klinisch zeigt sich dies mit allen Zeichen des Kreislaufversagens im Zusammenhang mit einer systemischen Infektion. Die Unterschiede zur klinischen Manifestation einer kardialen Dysfunktion bei Patienten mit dekompensierter Herzinsuffizienz nichtseptischer Ätiologie liegen in den Besonderheiten der veränderten globalen hämodynamischen Parameter (Vorlast, Nachlast, Mikro- zirkulation). Im Gegensatz zu anderen myokardialen Pathologien ist daher für die septische Kardiomyopathie ein multimodaler Ansatz für die Diagnostik und die Therapiesteuerung erforderlich. Im Folgenden werden die wichtigsten verfügbaren, intensivmedizinischen Parameter und Methoden zusammengefasst und in den Kontext ihrer derzeitigen Relevanz für die Diagnostik und Therapiesteuerung der septischen Kardiomyopathie eingeordnet.

\section{Klinischer Verlauf und Prognose}

Aufgrund der Komplexität der Diagnosestellung und Quantifizierung der septischen Kardiomyopathie ist eine Prognosestellung in der Akutphase der Erkrankung schwierig. Gleiches gilt für die Beschreibung desklinischen Verlaufs. Trotz der ausgeprägten Heterogenität der eingesetzten Methoden zur Diagnosestellung findet häufig eine Reduktion der linksventrikulären Ejektionsfraktion (LVEF) im klinischen Alltag als Synonym der linksventrikulären Dysfunktion Gebrauch. Zu beachten ist hierbei, dass es im Rahmen des septischen Schocks neben einer Umverteilung des Blutflusses zwischen den Organsystemen zu einer absoluten oder relativen Hypovolämie (reduzierte Vorlast) und einer Reduktion des vaskulären Tonus (reduzierte Nachlast) kommt. Insbesondere die Reduktion des vaskulären Tonus (reduzierte Nachlast) kann temporär die kardiale Dysfunktion im Rahmen des septischen Schocks maskieren (erhaltene LVEF bei bereits manifester myokardialer Dysfunktion). Es ist in diesem Zusammenhang von entschei- dender Bedeutung, sich vor Augen zu führen, dass die LVEF vielmehr den vaskulären Tonus als die myokardiale Kontraktilität widerspiegelt [88]. An dieser Stelle wird noch einmal der wichtige Zusammenhang zwischen „cardiac output“ (CO) und systemisch vaskulärem Widerstand (SVR) erwähnt. Werdan et al. untersuchten in 31 Patienten mit sepsisassoziiertem Multiorganversagen die Korrelation zwischen CO und SVR. Mit abnehmender Nachlast (Abfall des SVR) steigt (bis zu physiologischen Grenzen) das CO. Eine Erhöhung des SVR (z. B. durch vasoaktive Substanzen) führt hingegen $\mathrm{zu}$ einer Abnahme des $\mathrm{CO}$ und zur Demaskierung einer etwaigen myokardialen Dysfunktion [107].

Seit den Untersuchungen von Parker et al. aus den Jahren 1984 und 1990 [82, 83] wird die Frage der Prognose der septischen Kardiomyopathie kontrovers diskutiert [111]. Die Autoren beschrieben, dass überlebende Patienten im septischem Schock, im Vergleich zu später verstorbenen Patienten, eine reduzierte links- und rechtsventrikuläre EF sowie eine ausgeprägte linksventrikuläre Dilatation aufwiesen [82, 83]. Seit diesen Pionierarbeiten untersuchten diverse (meist kleine) klinische Studien die Frage nach der Prognose der septischen Kardiomyopathie. Eine jüngst erschienene Metaanalyse, die 62 Originalarbeiten (mit über 700 Patienten) mit dieser Fragestellung zusammenfasst, konnte zeigen, dass sich zwischen überlebenden Patienten mit septischem Schock im Vergleich zu verstorbenen Patienten kein Unterschied in links- und rechtsventrikulärer EF zeigt [39]. Diese Metaanalyse widerlegt zum einen die Ergebnisse von Parker et al. und wirft zugleich erneut die Frage nach der Relevanz der links- und rechtsventrikulären EF im klinischen Verlauf und in der Prognose der septischen Kardiomyopathie auf. Mit dem Verständnis, dass die LVEF eng mit der linksventrikulären Nachlast assoziiert ist, lassen sich die Ergebnisse von Parker et al. neu interpretieren. Patienten mit niedriger LVEF haben keinen Überlebensvorteil; vielmehr ist die erhöhte Letalität von Patienten mit einer niedrigen linksventrikulären Nachlast (und normaler LVEF) durch die persistieren- 
de ausgeprägte Vasoplegie als Ausdruck einer hohen Krankheitsschwere zu erklären [88]. Zusammenfassend bleiben große klinische Studien mit neuen methodischen Ansätzen zur Diagnose der septischen Kardiomyopathie abzuwarten, um die Frage der Prognose der septischen Kardiomyopathie suffizient beantworten zu können.

\section{Hämodynamisches Monitoring und Elektrokardiographie}

Invasiv gemessene arterielle und venöse Blutdrücke stellen wichtige, wenngleich mit einem erhöhten Komplikationsrisiko verbundene, Methoden zu Diagnosestellung und Therapieüberwachung bei kritisch kranken Patienten dar. Dabei ist für den zentralen Venendruck seit Längerem bekannt, dass dieser im septischen Schock nur schlecht mit dem linksventrikulären enddiastolischen Druck (LVEDP), also dem optimalen linksventrikulären Füllungsdruck, korreliert [81]. Der pulmonalarterielle Katheter (PAK) ermöglicht im Gegensatz zum zentralen Venenkatheter (ZVK) eine deutlich differenziertere Messung der hämodynamischen Verhältnisse. So können u. a. $\mathrm{CO}$ sowie pulmonalarterieller und systemischer Gefäßwiderstand ermittelt werden. Außerdem stellt die per PAK ermittelte gemischtvenöse Sättigung in den Pulmonalgefäßen ein indirektes Korrelat für das Sauerstoffangebot bzw. dessen Ausschöpfung dar. Der perioperative Einsatz des PAK ist allerdings mit der Ausnahme von herzchirurgischen Patienten nicht weit verbreitet [26]. Sein Einsatz scheint aufgrund seines signifikanten Risikoprofils nur bei Rechtsherzinsuffizienz, pulmonalarteriellem Hypertonus und im Rahmen von komplexen, operativen Eingriffen (v. a. in der Kardiochirurgie und in der Gefäßchirurgie) gerechtfertigt [93]. Eine klare Empfehlung für den Einsatz in der Sepsis gibt es nicht, wenngleich einzelne $\mathrm{Au}$ toren einen Einsatz im Zusammenspiel mit der Echokardiographie im Rahmen eines multimodalen Diagnostikansatzes für die septische Kardiomyopathie befürworten [44].

Die weniger invasiven Pulskonturanalyseverfahren zeigen eine starke Abhän- gigkeit vom systemischen Gefäßwiderstand. Da dieser in der Sepsis stark variieren kann, ist dieses Verfahren für die Diagnostik der septischen Kardiomyopathie nur eingeschränkt verwendbar [29]. Ein 12-Kanal-EKG ist einfach durchzuführen und sollte daher bei angenommener kardialer Dysfunktion zur selbstverständlichen bettseitigen Basisdiagnostik gehören. Allerdings sind mit einer septischen Kardiomyopathie assoziierte EKGVeränderungen relativ unspezifisch und können daher bei unklarer Grunderkrankung ein akutes Koronarsyndrom vortäuschen [52].

\section{Laborparameter}

Neben den klassischen Parametern der Inflammation wie Prokalzitonin (PCT), dem C-reaktiven Protein (CRP) und der Leukozytenzahl, können Marker einer Herzinsuffizienz wie das N-terminale pro B-Typ natriuretische Peptid (NT-proBNP) die Diagnose erleichtern [14]. In einer aktuellen Untersuchung an über 900 Patienten zeigten sich sowohl NT-proBNP als auch hochsensitives kardiales Troponin T (hs-cTNT) hochgradig mit der Ausbildung eines septischen Schocks (mit und ohne septische Kardiomyopathie) assoziiert. In dieser Untersuchung war NT-pro-BNP als Prädiktor der Neunzigtageletalität der Patientenpopulation dem hs-cTNT überlegen [71]. Diese Untersuchung zeigt jedoch auch, dass sowohl NT-pro-BNP als auch hscTNT im Hinblick auf die Diagnose einer septischen Kardiomyopathie nur eine niedrige Spezifität aufweisen.

\section{Echokardiographie}

Führendes Problem bei der Ermittlung der Herzfunktion in der Sepsis ist die in der Regel isolierte Betrachtung des Herzens unter Missachtung der extrakardialen Kreislaufsituation. Kein derzeit verfügbares Messverfahren vereint die Evaluierung von Herz und Kreislauf suffizient [33]. Auch wenn eine echokardiographische Untersuchung beim septischen, hämodynamisch-instabilen Patienten unabdingbar ist, steht die Echokardiographie für die Erfassung des Ausmaßes der septischen Kardiomyopa- thie seit Jahren in der wissenschaftlichen Diskussion. Die Evaluation der kardialen Funktion mittels konventioneller echokardiographischer Parameter (LVEF) ist, wie bereits angemerkt, zumeist durch Veränderungen des komplexen Systems aus Vor- und Nachlast beeinflusst. Weiterführende echokardiographische Verfahren zur Quantifizierung der linksund rechtsventrikulären Kontraktilität, wie z.B. der mittels Gewebe-Doppler ermittelte „myocardial performance index (MPI)“ und "myocardial velocity index (MVI)“ sind durch deren Winkelabhängigkeit und fehlende Reproduzierbarkeit limitiert. Eine neuere Methode der Quantifizierung der direkten kardialen Funktion stellt die Messung der "strain“ und „strain rate“ mithilfe des multiplanaren Gewebe-Doppler oder mithilfe von „speckle tracking “ dar. Letzteres hat gegenüber dem Gewebedoppler den großen Vorteil, dass es retrospektiv und winkelunabhängig durchgeführt werden kann [35]. Die Methode des „speckle tracking“ wurde erstmals 2004 beschrieben. Sie basiert auf einem semiautomatischen Algorithmus, der die Verschiebung von akustischen „speckles“ im Myokard verfolgt. Im Vergleich zur LVEF unterliegt diese "Speckle“Verschiebung einer deutlich geringeren Beeinflussung durch Vor- und Nachlast sowie durch Veränderungen der myokardialen „Compliance“, da es die myokardiale Deformation direkt quantifiziert [78]. Die Untersuchungen von Shahul et al. verdeutlichen dies: Die Autoren evaluierten bei 35 Patienten mit septischem Schock und erhaltener EF sowie bei 15 Patienten mit Sepsis und erhaltener EF mittels „speckle tracking“ die „longitudinalen strains“ $\mathrm{zu}$ den Zeitpunkten Diagnosestellung und 24 h später. Die ,globalen longitudinalen strains" verschlechterten sich signifikant über $24 \mathrm{~h}$ in der Gruppe der Patienten mit septischem Schock (auch nach Adjustierung gegen LVEDP und gegen den Einsatz von Vasopressoren), wohingegen die Gruppe der Patienten mit Sepsis kein Unterschied aufwies [94]. Die neuere SPECKS-Studie liefert weitere Evidenz für den Einsatz der „Speckle-tracking“Echokardiographie. $\mathrm{Ng}$ et al. konnten zeigen, dass Patienten im septischen 
Tab. 2 Klassifikation des „Afterload-related cardiac performance" (ACP)

\begin{tabular}{|l|l|}
\hline Kardiale Funktion & ACP (\%) \\
\hline Normal & $>80$ \\
\hline Leicht eingeschränkt & $60-80$ \\
\hline Moderat eingeschränkt & $40-60$ \\
\hline Schwer eingeschränkt & $<40$ \\
\hline
\end{tabular}

Schock, im Vergleich zu Patienten mit Sepsis, signifikant schlechtere globale und segmentale "longitudinale strains" aufwiesen [78]. Diese Ergebnisse belegen eine potenzielle Rolle der „Speckletracking"-Echokardiographie in der septischen Kardiomyopathie, auch wenn große randomisierte, klinische Studien bisher fehlen.

\section{„Afterload-related cardiac performance ${ }^{\prime \prime}$}

Eine vorgeschlagene Möglichkeit der Verbesserung einer Prognosestellung ist die zu der Echokardiographie komplementäre Quantifizierung der myokardialen Leistungsfähigkeit mittels erweitertem hämodynamischen Monitoring. So zeigten Werdan et al. bereits 2011, dass eine auf die Nachlast bezogene kardiale Leistungsfähigkeit („afterloadrelated cardiac performance, $\mathrm{ACP}$ “) bei $63 \%$ der verstorbenen Patienten in ihrer Studie einen Wert unter $60 \%$ aufwiesen. Hingegen zeigten $75 \%$ der Überlebenden einen ACP über $60 \%$ (• Tab. 2; [107]).

$$
\operatorname{ACP}(\%)=\frac{100 \times \mathrm{CO}}{\left\{\begin{array}{c}
560.68 \times((\mathrm{MAP}-\mathrm{CVP}) \\
\times 80 \div \mathrm{CO})^{-0,645}
\end{array}\right\}}
$$

$A C P$ „Afterload-related cardiac performance", $C O$ cardiac output, MAP (mittlerer arterieller Blutdruck), CVP zentraler Venendruck

Auch wenn die ACP weiterhin die Vorlast unberücksichtigt lässt, zeigt eine jüngere Untersuchung an 141 Patienten die potenzielle Bedeutung des ACP in der Prognose der septischen Kardiomyopathie. Im Gegensatz zum CO oder dem "cardiac power index" korrelierte ACP mit der Dreißigtagesterblichkeit [108].

Zusammenfassend lässt sich für die Diagnose und die Therapiesteuerung der septischen Kardiomyopathie feststellen, dass derzeit nur ein multimodaler Ansatz aus Klinik, Laborparametern, invasiven hämodynamischen Messgrößen und bettseitiger Ultraschallbildgebung eine adäquate Diagnosestellung und Therapiesteuerung der septischen Kardiomyopathie erlaubt.

\section{Therapie der septischen Kardiomyopathie}

Obwohl die septische Kardiomyopathie eine komplexe Erkrankung ist, sieht man sie simplifiziert immer noch als reversible Dysfunktion des rechten und linken Ventrikels [3]. Eine spezifische Therapie der kardialen Dysfunktion gibt es nicht, was vielleicht auch der Tatsache geschuldet ist, dass das Herz eher als "Opfer" in der Sepsis gesehen wird [3]. Die aktuell gültigen Leitlinien zur Behandlung des septischen Schocks stellen daher den Grundpfeiler in der Therapie der septischen Kardiomyopathie dar. Der folgende Abschnitt gibt eine Übersicht über (spezifischere) Therapieansätze von experimentellen Versuchen bis hin zur klinischen Anwendung und schließt mit einem Ausblick über mögliche, zukünftige Therapieansätze.

\section{Vasopressoren}

Die derzeit gültigen Leitlinien zur Therapie der Sepsis und des septischen Schocks empfehlen vorrangig den Einsatz von Noradrenalin als Vasopressor bei Patienten, die trotz adäquater Volumentherapie eine Hypotension aufweisen [89]. Generell sind $\alpha$-Rezeptorstimulierende Substanzen zu bevorzugen, die neben ihrem $a$-stimulierenden Effekt (mit resultierender Erhöhung der linksventrikulären Nachlast bei gleichzeitiger potenzieller Abnahme des CO) je nach Substanz einen unterschiedlichen, $\beta$-stimulierenden Effekt (Noradrenalin $<$ Dopamin $<$ Adrenalin) haben, der u. a. positive Effekte auf die Gewebsperfusion und einen positiven Effekt auf das rechte Herz hat [19].

Dopamin und Noradrenalin sind die am häufigsten untersuchten Vasopressoren in der Behandlung des septischen Schocks [115]. Neben den genannten $\beta$-stimulierenden Effekten hemmt Adrenalin die Durchblutung im Splanchnikusgebiet, verursacht mehr Arrhythmien und einen durch Erhöhung der Herzfrequenz gesteigerten Sauerstoffverbrauch im Myokard, sodass Adrenalin in der Behandlung der septischen Kardiomyopathie eine untergeordnete Rolle spielt. Das v. a. im angloamerikanischen Sprachraum genutzte Dopamin zeigte sich im Hinblick auf die Letalität sowie unerwünschte Nebenwirkungen wie Arrhythmien und Herzfrequenz in mehreren Metaanalysen dem Norepinephrin unterlegen [3, 115], obwohl randomisierte klinische Studien (RCT) keinen eindeutigen Vorteil für Noradrenalin belegen konnten [67, 85]. Eine multizentrische RCT untersuchte 1679 Patienten mit einem Schock unterschiedlicher Genese. Von den 858 Patienten mit Dopamin als erstem Vasopressor und 821 Patienten mit Norepinephrin als erstem Vasopressor hatten 63,2\% resp. $61,1 \%$ eine Sepsis als Ursache des Schocks [21]. Die Letalität der gesamten Patientengruppen auf der Intensivstation war mit Dopamin tendenziell höher als mit Noradrenalin $(50,2 \%$ vs. $45,9 \%$; $p=0,07)$ und war am Ende des Krankenhausaufenthalts $(59,4 \%$ vs. $56,6 \%$; $p=0,24)$ sowie bis nach 12 Monaten vergleichbar hoch $(65,9 \%$ vs. $63,0 \%$; $p=0,34)$ [21]. Basierend auf diesen Daten ist Noradrenalin der zu präferierende Vasopressor in der Therapie des septischen Schocks bzw. der septischen Kardiomyopathie.

Neben den oben genannten Vasopressoren ist Vasopressin ein potenter Vasopressor, der direkt über $\mathrm{V}_{1}$-Rezeptoren wirkt und die Wirkung anderer Vasopressoren verstärken kann [3]. Russel et al. untersuchten in der 2008 publizierten VASST-Studie den Einsatz von Vasopressin bei Patienten mit septischem Schock und Norepinephrintherapie im Hinblick auf die 28-Tage- und die Neunzigtageletalität. Analog zu weiteren RCT zeigte sich auch in dieser Studie kein Vorteil der Vasopressin- und Norepinephrintherapie im Hinblick auf das Überleben der Patienten [59, 73, 91]. Diese Untersuchungen belegen eine Stellung von Vasopressin als Reservetherapeutikum im therapierefraktären septischen Schock, spre- 
chen jedoch gegen den Einsatz von Vasopressin als Erst- oder „Single“-Vasopressor in der Therapie des septischen Schocks.

\section{Inotropika}

Auch wenn die derzeit gültigen Leitlinien zur Therapie des septischen Schocks den Einsatz von Dobutamin bei Patienten mit persistierender Hypoperfusion, trotz adäquater Volumentherapie und Einsatz eines Vasopressors, empfehlen [89], stehen die Dobutamintherapie und deren Dosis zur Behandlung der septischen Kardiomyopathie seit Jahren in der wissenschaftlichen Diskussion. Ältere experimentelle Arbeiten belegen potenziell positive Effekte von Dobutamin $\left(5 \mu \mathrm{g} \times \mathrm{kgKG}^{-1} \times \mathrm{min}^{-1}\right)$ auf die Mikrozirkulation und Durchblutung im Splanchnikusgebiet [20]. Gordon et al. [31] untersuchten in einer großen Studie an 516 Patienten den therapeutischen Nutzen einer zusätzlichen Levosimendantherapie bei Patienten mit Sepsis. Die Ergebnisse dieser Studien belegen, dass die zusätzliche Therapie mit Levosimendan weder einen Einfluss auf das Auftreten und die Schwere einer Organdysfunktion noch auf die Sterblichkeit hat. Im Gegenteil, eine Therapie mit Levosimendan war mit einer erhöhten Wahrscheinlichkeit eines prolongierten Weanings und eines erhöhten Risikos an supraventrikulären Tachykardien assoziiert [20]. Nadeem et al. beschreiben in einer Metaanalyse mit 83 Originalarbeiten, dass der Einsatz von Dobutamin im septischen Schock mit einem erhöhten „stroke work index“, einem erhöhtem pulmonalarteriellen Druck sowie einem reduzierten mittleren arteriellen Druck (MAP) assoziiert ist. Die Autoren konnten des Weiteren zeigen, dass die Therapie mit Dobutamin in einer reduzierten Herzfrequenz, einem erhöhtem CO sowie einem reduzierten Sauerstoffangebot bei erhöhter Sauerstoffausschöpfung resultierte [75]. Eine große RCT untersuchte des Weiteren den Einfluss einer Kombinationstherapie aus Dobutamin und Norepinephrin im Vergleich zu einer Adrenalintherapie bei 330 Patienten mit septischem Schock [2]. Es ergab sich kein Einfluss auf das 28-Tage-Überleben zwischen den Gruppen. Die fehlende eindeutige Evidenz für einen positiven Effekt einer Dobutamintherapie in der septischen Kardiomyopathie, trotz diverser großer klinischer Studien, zeigt zum einen, dass die zahlenmäßige Verbesserung einzelner kardialer/hämodynamischer Parameter keine uneingeschränkte Translation auf das Outcome der Patienten zulässt und wirft zum anderen die Frage nach der richtigen Dosis von Dobutamin in der Therapie der septischen Kardiomyopathie auf. Bis zur Klärung dieser Fragen durch weitere große RCT kann Dobutamin (bis zu $20 \mu \mathrm{g} \times \mathrm{kgKG}^{-1} \times$ $\min ^{-1}$ ), analog der gültigen Leitlinien zur Therapie des septischen Schocks, bei Patienten mit persistierender Hypoperfusion (bei vermutetem insuffizienten CO) trotz adäquater Volumentherapie und dem Einsatz eines Vasopressors als Inotropikum eingesetzt werden [89].

Im Gegensatz zu Dobutamin, das seine Hauptwirkung über die Stimulation kardialer $\beta_{1}$-Rezeptoren ausübt, ist Levosimendan ein „Ca ${ }^{2+}$ sensitizer“ und Inodilator, der zusätzlich immunmodulierende und antiapoptotische Effekte aufweist. Zumindest bei fortgeschrittener, dekompensierter Herzinsuffizienz ließen sich positive Effekte im Hinblick auf reduzierte proinflammatorische Zytokine, antioxidative Effekte und geringere BNPSpiegel im Vergleich zu Dobutamin feststellen [4]. Die positiven Effekte von Levosimendan in der Sepsis werden kontrovers diskutiert: Experimentelle Untersuchungen in diversen Tiermodellen des septischen Schocks konnten eine Verbesserung der linksventrikulären Kontraktilität und globalen Hämodynamik, eine reduzierte metabolische Acidose sowie eine abgeschwächte Organdysfunktion (Leber, Nieren und Lungen) belegen $[8,103,105,115]$. Ähnliche positive Effekte einer Levosimendantherapie zeigten mehrere (kleinere) klinische Studien bei Patienten mit septischem Schock $[25,115]$. Zangrillo et al. fassen die aktuell vorhandene Evidenz aus 7 RCT für den Einsatz von Levosimendan in ihrer systematischen Übersichtsarbeit zusammen [113]. Die Autoren schlussfolgern, dass die Therapie mit Levosimendan $\left(0,05-0,2 \mu \mathrm{g} \times \mathrm{kgKG}^{-1} \times \mathrm{min}^{-1}\right) \mathrm{im}$
Vergleich zu anderen (konventionellen) Inotropika mit einer signifikant reduzierten Letalität assoziiert ist (relatives Risiko -0.14). Die Autoren weisen jedoch auf die Heterogenität des genutzten Endpunkts Letalität (Krankenhausletalität: 2 Studien; 28-Tage-Letalität: 2 Studien; Dreißigtageletalität: 2 Studien, keine Angaben zur Studiendauer: eine Studie) sowie die suboptimale methodische Qualität von 4 der inkludierten 7 Studien hin. Auch unter Berücksichtigung der hohen Kosten einer Levosimendantherapie ist bei dieser relativ geringen und inhomogenen Evidenz der Einsatz von Levosimendan individuell kritisch abzuwägen.

Neben diesen pharmakologischen Ansätzen zur Steigerung der Kontraktilität untersuchten Thiele et al. in ihrer 2012 publizierten Arbeit den Benefit des Einsatzes einer „intra-aortic balloon pump“ (IABP) im Rahmen des kardiogenen Schocks. Die Untersuchung zeigt, dass der Einsatz der IABP zu keiner Reduktion der Dreißigtagesterblichkeit führt [101]. Auch wenn derzeit große klinische Studien zum Einsatz der IABP im Rahmen der septischen Kardiomyopathie fehlen, legt diese Arbeit nahe, dass die IABP im Rahmen des septischen Pumpversagens derzeit keinen Stellenwert hat.

\section{$\beta$-Rezeptoren-Blocker}

Pathophysiologisch geht eine Tachykardie immer mit einem erhöhten kardialen Sauerstoffverbrauch einher. Daher liegt es nahe, einen therapeutischen Ansatz in der Herzfrequenzreduktion bei Patienten mit septischer Kardiomyopathie zu sehen [115]. Der Einsatz von Esmolol zur Kontrolle der Herzfrequenz in der Sepsis wurde als offene, randomisierte Phase-2-Studie in einem Zentrum an insgesamt 144 Patienten im septischen Schock überprüft [74]. Ab einer Herzfrequenz von 95/min wurde Esmolol bei 77 Patienten so titriert, dass die Herzfrequenz zwischen $80 / \mathrm{min}$ und $94 / \mathrm{min}$ eingestellt war, und mit der Standardtherapie verglichen. Im Ergebnis konnten eine reduzierte 28 -Tage-Letalität $(80,5 \%$ vs. $49,4 \%$; $p<0,001)$ sowie eine um 5 Tage reduzierte, mediane Aufenthaltsdauer 
auf der Intensivstation belegt werden $(p=$ 0,03; [74]).

Allerdings warfen die Autoren selbst mehrere Fragen auf, die die Generalisierbarkeit ihrer Ergebnisse infrage stellen. Zum einen war die Letalität der Kontrollund Interventionsgruppe ungewöhnlich hoch, was die Frage nach einem selektierten Patientenkollektiv aufwirft. Zum anderen gibt die Studie keine Aufschlüsse darüber, ob und in welchem Umfang nichtkardiale Mechanismen zu diesem Ergebnis beigetragen haben [74]. Den Effekt einer reinen Herzfrequenzkontrolle sollte die Anwendung von Ivabradine (I [f] [funny channel current] inhibitor) klären. Eine entsprechende Studie zum Einsatz von Ivabradine auch beim septisch bedingten multiplen Organdysfunktionen $\left(\mathrm{MOD} I_{\mathrm{f}} \mathrm{Y}\right.$; NCT01186783) ist 2010 initiiert worden. Mit Ausnahme der Publikation des Studienprotokolls zusammen mit retrospektiven Daten [22] stehen weitere Informationen jedoch bisher aus (clinicaltrials.gov; Accession date 12.03.2017).

Andere Mechanismen einer $\beta$-Rezeptoren-Blockade, die neben der Herzfrequenzkontrolle diskutiert werden, sind Effekte auf Inflammation sowie Stoffwechsel und Gerinnung [40, 99]. Je nachdem, welche $\beta$-Rezeptoren blockiert werden, kann es zu vermehrter Inflammation ( $\beta_{2}$-Blockade) oder verminderter Inflammation ( $\beta_{1}$-Blockade) kommen [72]. Die vermuteten pleiotropen Effekte haben u. U. auch zu den widersprüchlichen Ergebnissen in Bezug auf reduzierte Herzfrequenz und ihre Assoziation mit einem Anstieg des Schlagvolumens beigetragen. Zumindest im experimentellen septischen Schock sind die vordergründig negativen Ergebnisse auf die Makrozirkulation (Abnahme des $\mathrm{CO}$ und des MAP) begleitet von einer verbesserten Mikrozirkulation des Intestinums. Induziert wurde der septische Schock an insgesamt 14 Schweinen durch Infusion von Pseudomonas aeruginosa. Nach Stabilisierung durch Volumentherapie wurde mit Esmolol $\left(7,5 \mu \mathrm{g} \times \mathrm{kgKG}^{-1} \times\right.$ $\min ^{-1}$ ) zwischen 90 und 300 min nach Bakterieninfusion therapiert, bis die Herzfrequenz unter 90/min fiel. Die Verbesserung der Mikrozirkulation in der mit Esmolol therapierten Gruppe könnte aber auch zumindest teilweise durch die vermehrte Gabe von Volumen erreicht worden sein (Esmololgruppe $625 \mathrm{ml}$ (500-938 ml) vs. Kontrollgruppe $250 \mathrm{ml}$ (250-438 ml); $p=0,093$; [41]).

Eine weitere experimentelle Studie untersuchte die Wirkung des ultrakurz wirksamen $\beta_{1}$-Rezeptoren-Blockers Landiolol (Halbwertzeit $4 \mathrm{~min}$ ) in einem Endotoxämiemodell am Schwein [55]. In diesem Model wurden repetitiv Landiolol (bis $200 \mu \mathrm{g} / \mathrm{kgKG}$ und min) vor und während einer LPS-Infusion $(100 \mu \mathrm{g}$ Bolus gefolgt von $1 \mu \mathrm{g} / \mathrm{kgKG}$ und $\mathrm{h}$ ) appliziert und die Hämodynamik und Gewebeoxygenierung zerebral gemessen. Kurita et al. konnten darstellen, dass die Dosierung eines $\beta$-RezeptorenBlockers nur nach einer Zielherzfrequenz nicht sinnvoll ist, sondern sogar die zerebrale Oxygenierung reduzieren kann. Dies gilt besonders bei einem Abfall des MAP und des HZV und bei höherer Dosierung des $\beta$-RezeptorenBlockers [55].

Zusammenfassend kann gefolgert werden, dass die Herzfrequenzkontrolle in der septischen Kardiomyopathie einen potenziellen therapeutischen Ansatz darstellen könnte. Das Fehlen von großen RCT lässt jedoch derzeit keine Empfehlung für den Einsatz von $\beta$-Rezeptoren-Blockern in der Therapie der septischen Kardiomyopathie zu.

\section{Fazit für die Praxis}

- Die Bedeutung der septischen Kardiomyopathie wird im klinischen Alltag häufig unterschätzt. Eine einheitliche Definition der septischen Kardiomyopathie gibt es bis heute nicht.

- Experimentelle und klinische Untersuchungen zur Verbesserung der Diagnosestellung sowie zur Identifikation neuer innovativer Therapieansätze in der septischen Kardiomyopathie sind dringend notwendig.

- Die Quantifizierung der myokardialen Leistungsfähigkeit in Abhängigkeit der Nachlast zusammen mit der "Speckle-tracking"-Echokardiographie könnten Methoden zur Verbesserung der Prognosestellung und
Therapiesteuerung der septischen Kardiomyopathie sein.

- Nach wie vor gibt es keine spezifischen Therapeutika für die Behandlung der septischen Kardiomyopathie. Die aktuell gültigen Leitlinien zur Behandlung des septischen Schocks stellen daher den Grundpfeiler in der Therapie der septischen Kardiomyopathie dar.

- Noradrenalin wird als Vasopressor der ersten Wahl bei Patienten mit septischem Schock, die trotz adäquater Volumentherapie eine Hypotension aufweisen, empfohlen.

- Dobutamin kann bei Patienten mit persistierender Hypoperfusion trotz adäquater Volumentherapie und des Einsatzes eines Vasopressors als Inotropikum eingesetzt werden.

- Aufgrund der hohen Kosten sowie der geringen und inhomogenen Evidenz ist der Einsatz von Levosimendan individuell kritisch abzuwägen.

- Die Herzfrequenzkontrolle könnte einen potenziellen therapeutischen Ansatz zur Behandlung der septischen Kardiomyopathie darstellen, jedoch fehlen bisher große randomisierte klinische Studien.

\section{Korrespondenzadresse}

Dr. med. L. Martin

Klinik für Operative Intensivmedizin und Intermediate Care, Uniklinik RWTH Aachen Pauwelsstraße 30, 52074 Aachen, Deutschland Imartin@ukaachen.de

Förderung. Diese Arbeit wurde unterstützt durch ein Forschungsstipendium der Deutschen Forschungsgemeinschaft an Lukas Martin (DFG, MA 7082/1-1).

\section{Einhaltung ethischer Richtlinien}

Interessenkonflikt. L. Martin, M. Derwall, C. Thiemermann und T. Schürholz geben an, dass kein Interessenkonflikt besteht.

Dieser Beitrag beinhaltet keine von den Autoren durchgeführten Studien an Menschen oder Tieren.

Open Access. Dieser Artikel wird unter der Creative Commons Namensnennung 4.0 International Lizenz (http://creativecommons.org/licenses/by/4.0/deed. de) veröffentlicht, welche die Nutzung, Vervielfältigung, Bearbeitung, Verbreitung und Wiedergabe in jeglichem Medium und Format erlaubt, sofern 
Sie den/die ursprünglichen Autor(en) und die Quelle ordnungsgemäßnennen, einen Link zur Creative Commons Lizenz beifügen und angeben, ob Änderungen vorgenommen wurden.

\section{Literatur}

1. Alhamdi Y, Abrams ST, Cheng Z et al (2015) Circulating histones are major mediators of cardiac injury in patients with sepsis. Crit Care Med 43:2094-2103115

2. Annane D, Vignon P, Renault A et al (2007) Norepinephrine plus dobutamine versus epinephrine alone for management of septic shock: a randomised trial. Lancet 370:676-684

3. Antonucci $\mathrm{E}$, Fiaccadori $\mathrm{E}$, Donadello $\mathrm{K}$ et al (2014) Myocardial depression in sepsis: From pathogenesis to clinical manifestations and treatment. JCrit Care 29:500-511

4. Avgeropoulou C, Andreadou I, MarkantonisKyroudis $S$ et al (2005) The $\mathrm{Ca}^{2+}$-sensitizer levosimendan improves oxidative damage, BNP and pro-inflammatory cytokine levels in patients with advanced decompensated heart failure in comparison to dobutamine. Eur J Heart Fail 7:882-887

5. Avlas O, Fallach R, Shainberg A et al (2011) Tolllike receptor 4 stimulation initiates an inflammatory response that decreases Cardiomyocyte contractility. Antioxid Redox Signal 15:1895-1909

6. Balija TM, Lowry SF (2011) Lipopolysaccharide and sepsis-associated myocardial dysfunction. Curr Opin Infect Dis 24:248-253

7. Ballard-Croft C, Maass DL, Sikes PJ, Horton JW (2007) Sepsis and burn complicated by sepsis alter cardiactransporter expression. Burns 33:72-80

8. Barraud D, Faivre V, Damy T et al (2007) Levosimendan restores both systolic and diastolic cardiac performance in lipopolysaccharidetreated rabbits: comparison with dobutamine and milrinone. Crit Care Med 35:1376-1382

9. Baumgarten $\mathrm{G}$, Knuefermann $\mathrm{P}$, Nozaki $\mathrm{N}$ et al (2001) In vivo expression of proinflammatory mediators in the adult heart after endotoxin administration: the role of toll-like receptor- 4 . JInfect Dis 183:1617-1624

10. Baumgarten $G$, Knuefermann $P$, Schuhmacher G (2006) Toll-like receptor 4, nitric oxide, and myocardial depression in endotoxemia. Shock 25:43-49

11. Boudina S, Sena S, Theobald H et al (2007) Mitochondrial energetics in the heart in obesity-related diabetes: direct evidence for increased uncoupled respiration and activation of uncoupling proteins. Diabetes 56:2457-2466

12. Böhm M, KirchmayrR, GierschikP, ErdmannE(1995) Increase of myocardial inhibitory G-proteins in catecholamine-refractory septic shock or in septic multiorgan failure. Am J Med 98:183-186

13. Brealey D, Brand M, Hargreaves I et al (2002) Association between mitochondrial dysfunction and severity and outcome of septic shock. Lancet 360:219-223

14. Charpentier J, Luyt C-E, Fulla Y et al (2004) Brain natriuretic peptide: A marker of myocardial dysfunction and prognosis during severe sepsis. Crit Care Med 32:660-665

15. Cimolai MC, Alvarez S, Bode C, Bugger H (2015) Mitochondrial mechanisms in septic cardiomyopathy. Int J Mol Sci 16:17763-17778

16. Coalson JJ, Hinshaw LB, Guenter CA et al (1975) Pathophysiologic responses of the subhuman primate in experimental septic shock. Lab Invest 32:561-569

17. Cohen J (2002) The immunopathogenesis of sepsis. Nature 420:885-891

18. Cunnion RE, Schaer GL, Parker MM et al (1986) The coronary circulation in human septic shock. Circulation 73:637-644

19. De Backer D, Scolletta S (2013) Clinical management of the cardiovascular failure in sepsis. Curr Vasc Pharmacol 11:222-242

20. De Backer D, Creteur J, Dubois M-J et al (2006) The effects of dobutamine on microcirculatory alterations in patients with septic shock are independent of its systemic effects. Crit Care Med 34:403-408

21. De Backer D, Biston P, Devriendt J et al (2010) Comparison of Dopamine and Norepinephrine in the treatment of shock. N Engl J Med 362:779-789

22. De Santis V, Frati G, Greco E, Tritapepe L (2014) Ivabradine: a preliminary observation for a new terapeutic role in patients with multiple organ dysfunction syndrome. Clin Res Cardiol 103:831-834

23. Edovitsky E (2006) Role of endothelial heparanase in delayed-type hypersensitivity. Blood 107:3609-3616

24. Ehrentraut S, Lohner R, Schwederski M et al (2011) In vivo toll-like receptor 4 antagonism restores cardiac function during endotoxemia. Shock 36:613-620

25. Erb J, Beutlhauser T, Feldheiser A et al (2014) Influence of levosimendan on organ dysfunction in patients with severely reduced left ventricular function undergoing cardiac surgery. J Int Med Res 42:750-764

26. Evans DC, Doraiswamy VA, Prosciak MP et al (2009) Complications associated with pulmonary artery catheters: a comprehensive clinical review. Scand Surg 98:199-208

27. Fallach R, Shainberg A, Avlas $O$ et al (2010) Cardiomyocyte Toll-like receptor 4 is involved in heart dysfunction following septic shock or myocardial ischemia. J Mol Cell Cardiol 48:1236-1244

28. Fernandes CJ, de Assuncao MSC (2012) Myocardia dysfunction in sepsis: a large, unsolved puzzle. Crit Care Res Pract 2012:1-9. doi:10.1155/2012/ 896430

29. Ganter MT, Al-Shabasy AM, Schott P et al (2016) Continuous cardiac output measurement by uncalibrated pulse wave analysis and pulmonary artery catheter in patients with septic shock. J Clin Monit Comput 30:13-22

30. Gao M, Ha T, Zhang X et al (2012) Toll-like receptor 3 plays a central role in cardiac dysfunction during polymicrobial sepsis. Crit Care Med 40:2390-2399

31. Gordon AC, Perkins GD, Singer M, McAuley DF, Orme RML, Santhakumaran SCB, Mason AJ, Cross M, Al-Beidh F, Best-Lane J, Brealey D, Nutt CL, McNamee JJ, Reschreiter H, Breen A, Liu KD, Ashby D (2016) Levosimendan for the prevention of acute organ dysfunction in sepsis. N Engl J Med 375:1638-1648. doi:10.1056/NEJMoa1609409

32. Grandel U, Hopf $M$, Buerke $M$ et al (2005) Mechanisms of cardiac depression caused by Lipoteichoic acids from staphylococcus aureus in isolated rat hearts. Circulation 112:691-698

33. Guarracino F, Baldassarri R, Pinsky MR (2013) Ventriculo-arterial decoupling in acutely altered hemodynamic states. Crit Care 17:213

34. Hagiwara S, Iwasaka H, Uchino T, Noguchi T (2008) High mobility group box 1 induces a negative Inotropic effect on the left ventricle in an isolated ratheartmodel of septicshock. Circ J72:1012-1017
35. Helle-Valle T, Crosby J,Edvardsen Tet al (2005) New noninvasive method for assessment of left ventric ular rotation: speckle tracking echocardiography. Circulation 112:3149-3156

36. Hinshaw LB, Archer LT, Spitzer JJ et al (1974) Effects of coronary hypotension and endotoxin on myocardial performance. Am J Physio 227:1051-1057

37. Hobai IA, Edgecomb J, LaBarge K, Colucci WS (2015) Dysregulation of intracellular calcium transporters in animal models of sepsis-induced cardiomyopathy. Shock 43:3-15

38. Hotchkiss RS, Rust RS, Dence CS et al (1991) Evaluation of the role of cellular hypoxia in sepsis by the hypoxic marker [18F]fluoromisonidazole. Am JPhyiol 261:R965-R972

39. Huang SJ, Nalos M, McLean AS (2013) Is early ventricular dysfunction or dilatation associated with lower mortality rate in adult severe sepsis and septic shock? A meta-analysis. Crit Care 17:R96

40. Ince C (2015) To beta block or not to beta block; that is the question. Crit Care 19:339

41. Jacquet-Lagrèze $M, A$ Alaouchiche $B$ (2015) Gut and sublingual microvascular effect of esmolol during septic shock in a porcine model. Crit Care 19:241

42. Johnson GB, Brunn GJ, Kodaira Y, Platt JL (2002) Receptor-mediated monitoring of tissue wellbeing via detection of soluble heparan sulfate by Toll-like receptor 4. J Immunol 168:5233-5239

43. Johnson GB, Brunn GJ, Platt JL (2004) Cutting edge: an endogenous pathway to systemicinflammatory response syndrome (SIRS)-like reactions through Toll-like receptor 4. JImmunol 172:20-24

44. JozwiakM,PersichiniR, MonnetX, TeboulJ-L(2011) Management of myocardial dysfunction in severe sepsis. Semin Respir Crit Care Med 32:206-214

45. Kakihana Y, Ito T, Nakahara M et al (2016) Sepsisinduced myocardial dysfunction: pathophysiology and management. JIntensive Care 4:22

46. Kalbitz M, Grailer JJ, Fattahi F et al (2015) Role of extracellular histones in the cardiomyopathy of sepsis. FASEB J 29:2185-2193

47. Khan SA, Skaf MW, Harrison RW et al (2003) Nitric oxide regulation of myocardial contractility and calcium cycling: independent impact of neuronal and endothelial nitric oxide synthases. Circ Res 92:1322-1329

48. Kimmoun A, Levy B (2011) Treatment of myocardial dysfunction in sepsis: the Toll-like receptor antagonist approach. Shock 36:633-634

49. Kirov MY, Evgenov OV, Evgenov NV et al (2001) Infusion of methylene blue in human septic shock: A pilot, randomized, controlled study. Crit Care Med 29:1860

50. Knuefermann P (2004) Toll-like receptor 2 mediates staphylococcus aureus-induced myocardial dysfunction and Cytokine production in the heart Circulation 110:3693-3698

51. Knuefermann P, Nemoto S, Misra A et al (2002) CD14-deficient mice are protected against lipopolysaccharide-induced cardiac inflammation and left ventricular dysfunction. Circulation 106:2608-2615

52. Krishnagopalan S, Kumar A, Parrillo JE, Kumar A (2002) Myocardial dysfunction in the patient with sepsis. Curr Opin Crit Care 8:376

53. Kumar A, Thota V, Dee Let al (1996) Tumor necrosis factor alpha and interleukin 1 beta are responsible for in vitro myocardial cell depression induced by human septicshockserum.JExpMed 183:949-958

54. Kumar A, Brar R, Wang P et al (1999) Role of nitric oxide and CGMP in human septic serum-induced depression of cardiac myocyte contractility. Am J Physiol 276:R265-76 
55. Kurita T, Kawashima S, Morita K, Nakajima $Y$ (2017) Use of a short-acting $\beta 1$ blocker during Endotoxemia may reduce cerebral tissue oxygenation if Haemodynamics are depressed by a decrease in heart rate. Shock 47(6):765-771. doi:10.1097/shk.0000000000000795

56. Lalu MM, Gao CQ, Schulz R (2003) Matrix metalloproteinase inhibitors attenuate endotoxemia induced cardiac dysfunction: A potential role for MMP-9. MolCell Biochem 251:61-66

57. Landesberg G, Levin PD, Gilon D et al (2015) Myocardial dysfunction in severe sepsis and septic shock - no correlation with inflammatory cytokines in real-life clinical setting. Crit Care Med 148:93-102

58. Larche J, Lancel S, Hassoun SM et al (2006) Inhibition of Mitochondrial permeability transition prevents sepsis-induced myocardial dysfunction and mortality. J Am Coll Cardiol 48:377-385

59. Lauzier F, Lévy B, Lamarre P, Lesur O (2006) Vasopressin or norepinephrine in early hyperdynamic septic shock: a randomized clinical trial. Int Care Med 32:1782-1789

60. Lee WL, Slutsky AS (2010) Sepsis and endothelial permeability. N Engl J Med 363:689-691

61. Levy RJ, Vijayasarathy C, Raj NR et al (2004) Competitive and noncompetitive inhibition of myocardial Cytochrome C Oxidase in sepsis. Shock 21:110-114

62. Li J-P, Vlodavsky I (2009) Heparin, heparan sulfate and heparanase in inflammatory reactions. Thromb Haemost 102:823-828

63. Lohner R, Schwederski M, Narath C et al (2013) Toll-like receptor 9 promotes cardiac inflammation and heart failure during polymicrobial sepsis. Mediators Inflamm 2013:261049-261013

64. Maass DL, White J, Horton JW (2002) IL-1beta and IL-6 act synergistically with TNF-alpha to alter cardiac contractile function after burn trauma. Shock 18:360-366

65. Manon-Jensen T, Itoh Y, Couchman JR (2010) Proteoglycans in health and disease: the multiple roles of syndecan shedding. FEBS J 277:3876-3889

66. Marshall M, Anilkumar N, Layland J et al (2009) Protein phosphatase 2A contributes to the cardiac dysfunction induced by endotoxemia. Cardiovasc Res 82:67-76

67. Martin C, Papazian L, Perrin G et al (1993) Norepinephrine or dopamine for the treatment of hyperdynamic septic shock? Crit Care Med 103:1826-1831

68. Martin L, Peters C, Schmitz S et al (2015) Soluble Heparan sulfate in serum of septic shock patients induces Mitochondrial dysfunction in murine Cardiomyocytes. Shock 44:569-577

69. Martin L, Schmitz S, De Santis Ret al (2015) Peptide 19-2.5 inhibits heparan sulfate-triggered inflammation in murine cardiomyocytes stimulated with human sepsis serum. PLoSONE 10:e0127584

70. Martin L, Koczera P, Zechendorf E, Schuerholz T (2016) The Endothelial Glycocalyx: new diagnostic and therapeutic approaches in sepsis. Biomed Res Int 2016:1-8

71. Masson S, Caironi P, Fanizza C, Carrer S (2016) Sequential N-terminal pro-B-Type natriuretic peptide and high-sensitivity cardiac troponin measurements during albumin replacement in patients with severe sepsis. Crit Care 18:R6

72. de Montmollin E, Aboab J, Mansart A, Annane D (2009) Bench-to-bedside review: beta-adrenergic modulation in sepsis. Crit Care 13:230

73. Morelli A, Ertmer C, Rehberg S et al (2009) Continuous terlipressin versus vasopressin infusion in septic shock (TERLIVAP): a randomized, controlled pilot study. Crit Care 13:R130-R132. doi:10.1186/ cC7990

74. Morelli A, ErtmerC, Westphal Metal (2013) Effect of heart rate control with Esmolol on hemodynamic and clinical outcomes in patients with septic shock. Crit Care 13:R130-2

75. Nadeem R, Sockanathan S, Singh M et al (2017) Impact of Dobutamine in patients with septic shock. Am J Ther 24(3):e333-e346. doi:10.1097/ mjt.0000000000000272

76. Natanson C, Eichenholz PW, Danner RL et al (1989) Endotoxin and tumor necrosis factor challenges in dogs simulate the cardiovascular profile of human septic shock. J Exp Med 169:823-832

77. Nemoto S, Vallejo JG, Knuefermann P et al (2002) Escherichia coli LPS-induced LV dysfunction: role of toll-like receptor-4 in the adult heart. Am J Physiol Heart Circ Physiol 282:H2316-23

78. Ng PY, Sin WC, Ng AK-Y, Chan WM (2016) Speckle tracking echocardiography in patients with septic shock: a case control study (SPECKSS). Crit Care 20:483-488

79. Niederbichler AD, Hoesel LM, Westfall MV et al (2006) An essential role for complement C5a in the pathogenesis of septic cardiac dysfunction. J Exp Med 203:53-61

80. Opal SM, Laterre P-F, Francois B et al (2013) Effect of eritoran, an antagonist of MD2-TLR4, on mortality in patients with severe sepsis: the ACCESS randomized trial. JAMA 309:1154-1162

81. Packmann MI, Rackow EC (1983) Optimum left heart filling pressure during fluid resuscitation of patients with hypovolemic and septic shock. Crit Care Med 11:165

82. Parker MM, Shelhamer JH, Bacharach SLetal (1984) Profound but reversible myocardial depression in patients with septic shock. Ann Intern Med 100:483-490

83. Parker MM, McCarthy KE, Ognibene FP, Parrillo JE (1990) Right ventricular dysfunction and dilatation, similar to left ventricular changes, characterize the cardiac depression of septic shock in humans. Crit Care Med 97:126-131

84. Parrillo JE, Burch C, Shelhamer JH et al (1985) A circulating myocardial depressant substance in humans with septic shock. Septic shock patients with a reduced ejection fraction have a circulating factor that depresses in vitro myocardial cell performance. JClin Invest 76:1539-1553

85. PatelGP,Grahe JS, Sperry Metal (2010) Efficacyand safety of dopamine versus norepinephrine in the management of septic shock. Shock 33:375-380

86. Piquereau J, Godin R, Deschênes S et al (2014) Protective role of PARK2/Parkin in sepsis-induced cardiac contractile and mitochondrial dysfunction. Autophagy 9:1837-1851

87. Raeburn CD, Calkins CM, Zimmerman MA et al (2002) ICAM-1 and VCAM-1 mediate endotoxemic myocardial dysfunction independent of neutrophil accumulation. Am J Physiol Regul Integr Comp Physiol 283:R477-86

88. Repessé X, Charron C, Vieillard-Baron A (2013) Evaluation of left ventricular systolic function revisited in septic shock. Crit Care 17:164

89. Rhodes A, Evans LE, Alhazzani W et al (2017) Surviving Sepsis Campaign:International Guidelines for Management of Sepsis and Septic Shock: 2016. Crit Care Med 45:486-552

90. Rolli J, Rosenblatt-Velin N, Li J et al (2010) Bacterial Flagellin triggers cardiac innate immune responses and acute contractile dysfunction. PLoS ONE 5:e12687-12

91. Russell JA, Walley KR, Singer J et al (2008) Vasopressin versus Norepinephrine infusion in patients with septic shock. N Engl J Med 358:877-887

92. Schmidt EP, Yang $Y$, Janssen WJ et al (2012) The pulmonary endothelial glycocalyx regulates neutrophil adhesion and lung injury during experimental sepsis. Nat Med 18:1217-1223

93. Schürholz T, Marx G (2012) Hämodynamisches Monitoring - Gibt es Indikationen für den perioperativen Einsatz des pulmonal-arteriellen Katheters? Anasthesiol Intensivmed Notfallmed Schmerzther 47:110-117

94. Shahul S, Gulati G, Hacker MRet al (2015) Detection of myocardial dysfunction in septic shock: a speckle-tracking Echocardiography study. Anesth Analg 121:1547-1554

95. Shepherd RE, Lang CH, McDonough KH (1987) Myocardial adrenergic responsiveness after lethal and nonlethal doses of endotoxin. Am J Physiol Heart Circ Physiol 252:H410-H416

96. Spronk PE, Zandstra DF, Ince C (2004) Benchto-bedside review: sepsis is a disease of the microcirculation. Crit Care 8:462-468

97. Suliman HB, Carraway MS, Piantadosi CA (2003) Postlipopolysaccharide oxidative damage of mitochondrial DNA. Am J Respir Crit Care Med 167:570-579

98. Suliman HB, Welty-Wolf KE, Carraway Met al (2004) Lipopolysaccharide induces oxidative cardiac mitochondrial damage and biogenesis. Cardiovasc Res 64:279-288

99. Suzuki T, Morisaki H, Serita R et al (2005) Infusion of the $\beta$-adrenergic blocker esmolol attenuates myocardial dysfunction in septic rats. Crit Care Med 33:2294-2301

100. Tang C, Liu MS (1996) Initial externalization followed by internalization of beta-adrenergic receptors in rat heart during sepsis. Am J Physiol 270:R254-R263

101. Thiele H, Zeymer U, Neumann F-J et al (2012) Intraaortic balloon support for myocardial infarction with cardiogenic shock. N Engl J Med 367:1287-1296

102. Tomita K, Takashina M, Mizuno N et al (2015) Cardiac fibroblasts: contributory role in septic cardiac dysfunction. J Surg Res 193:874-887

103. Tsao C-M, LiK-Y,Chen S-Jetal (2014) Levosimendan attenuates multiple organ injury and improves survival in peritonitis-induced septic shock:studies in a rat model. Crit Care 18:1683-1628

104. Vallejo JG (2011) Role of Toll-like receptors in cardiovascular diseases. Clin Sci 121:1-10

105. Wang X, Ma S, Liu Y et al (2014) Effects and mechanism analysis of combined infusion by levosimendan and vasopressin on acute lung injury in rats septic shock. Cell Biochem Biophys 70:1639

106. Wang X, Liu D, Chai W et al (2015) The role of uncoupling protein 2 during myocardial dysfunction in a canine model of Endotoxin shock. Shock 43:292-297

107. Werdan K, Oelke A, Hettwer S et al (2011) Septic cardiomyopathy: hemodynamic quantification, occurrence, and prognostic implications. Clin Res Cardiol 100:661-668

108. Wilhelm J, Hettwer S, Schuermann M et al (2013) Severity of cardiac impairment in the early stage of community-acquired sepsis determines worse prognosis. Clin Res Cardiol 102:735-744

109. Wu L-L, Yang S-L, Yang R-C et al (2003) G protein and Adenylate Cyclase complex-mediated signal Transduction in the rat heart during sepsis. Shock 19:533-537

110. Yang Y, Macleod V, Miao H-Q et al (2007) Heparanase enhances syndecan-1 shedding: a nove 
mechanism for stimulation of tumor growth and metastasis. J Biol Chem 282:13326-13333

111. Zaky A, Deem S, Bendjelid K, Treggiari MM (2014) Characterization of cardiac dysfunction in sepsis: an ongoing challenge. Shock 41:12-24

112. Zang QS, Sadek H, Maass DL et al (2012) Specific inhibition of mitochondrial oxidative stress suppresses inflammation and improves cardiac function in a rat pneumonia-related sepsis model. Am J Physiol Heart Circ Physiol 302(9):H1847-H1859

113. Zangrillo A, Putzu A, Monaco F et al (2015) Levosimendan reduces mortality in patients with severe sepsis and septic shock: A meta-analysis of randomized trials. J Crit Care 30:908-913

114. Zhang C, Mo M, Ding W et al (2014) Highmobility group box 1 (HMGB1) impaired cardiac excitation-contraction coupling by enhancing the sarcoplasmic reticulum (SR) $\mathrm{Ca}(2+)$ leak through TLR4-ROS signaling in cardiomyocytes. J Mol Cell Cardiol 74:260-273

115. Zhang Z, Chen K (2016) Vasoactive agents for the treatment of sepsis. Ann Transl Med 4:333-333

116. Zheng G, Lyu J, Liu S et al (2015) Silencing of uncoupling protein 2 by small interfering RNA aggravates mitochondrial dysfunction in cardiomyocytes under septic conditions. Int J Mol Med 35:1525-1536

\section{Deutscher Herzbericht 2016: Immer noch sterben mehr Frauen an Herzkrankheiten als Männer}

\section{Frauen mit Herzerkrankungen haben} eine schlechtere Prognose als Männer. Werden Frauen seltener behandelt und weniger gut versorgt? Die Deutsche Herzstiftung will eine genaue Ursachenanalyse.

Wie bereits in den Vorjahren sterben in der Summe mehr Frauen als Männer an Herzkrankheiten, wie der Deutsche Herzbericht 2016 dokumentiert. 110.915 Frauen gegenüber 97.061 Männern starben 2014 an KHK/Herzinfarkt, Herzklappenerkrankungen, Rhythmusstörungen, Herzinsuffizienz und angeborenen Herzfehlern. Besonders auffallend ist die deutlich höhere Sterblichkeit bei Frauen mit Herzinsuffizienz, Herzrhythmusstörungen und Herzklappenerkrankungen. Die Deutsche Herzstiftung unterstreicht: Diese starken Sterblichkeitsunterschiede bestehen seit Jahren, sie stehen im Kontrast zur stationären Erkrankungshäufigkeit, die bei Männern deutlich höher ist, und sollten Anlass für genauere Untersuchungen sein, um Engpässe in der medizinischen Versorgung von Herzpatientinnen auszuschließen. So lag 2014 die Sterbeziffer (Gestorbene pro 100.000 Einwohner/EW) bei Herzschwäche für Frauen um 71,2\% über dem Wert der Männer: bei Frauen lautete die Sterbeziffer 68,9 pro $100.000 \mathrm{EW}$, bei Männern 40,3. In absoluten Zahlen: 28.513 Frauen starben gegenüber 16.038 Männern an Herzschwäche. Bei den Herzrhythmusstörungen lag die Sterbeziffer der Frauen um 48,2\% höher (Frauen 37,8; Männer: 25,5): 15.620 Frauen starben gegenüber 10.154 Männern an Rhythmusstörungen. Bei Herzklappenerkrankungen lag die Sterbeziffer der Frauen um 54\% höher als bei den Männern. Eine Ausnahme stellen KHK/Herzinfarkt dar, die generell eine deutlich höhere Zahl an Sterbefällen bei Männern als bei Frauen aufweisen.

Frauen erhalten deutlich weniger LHK Für das Sterblichkeitsgefälle zwischen Frauen und Männern stellt sich die Frage nach Unterschieden in der medizinischen Versorgung (Diagnostik, Therapie). So zeigt sich in der Versorgung von Patienten mit Herzgefäßer- krankungen - auch unter Berücksichtigung der höheren Erkrankungshäufigkeit der KHK bei Männern -, dass deutlich weniger Frauen eine Linksherzkatheter-Untersuchung (LHK) erhalten: 2015 waren 35,4\% der LHKPatienten Frauen gegenüber 64,8\% Männern. Niedrig fällt auch der Frauenanteil bei den perkutanen Koronar-Interventionen (PCI) (Ballondilatation, Stent-Einbringung) aus: 2015 waren nur $28,3 \%$ der PCl-Patienten Frauen. Ähnlich verhält es sich bei den Bypass-Operationen: von 51.941 Eingriffen (2015) wurden Frauen mit 11.521 (22\%) Eingriffen deutlich seltener operiert als Männer (78\% mit 40.420 Bypass-Operationen). Ferner zeigen auch die verordneten ArzneiTagesdosen, dass Männer deutlich mehr Medikamente zur Behandlung von HerzKreislauf-Erkrankungen bekommen als Frauen: bei Männern sind $45 \%$ der verordneten Arzneien Herz-Kreislauf-Medikamente, bei Frauen liegt der Anteil bei 25\% (TK Gesundheitsreport 2016).

Ob ein Zusammenhang zwischen diesen Unterschieden in der medizinischen Versorgung von Herzpatientinnen und der ungünstigeren Prognose für Frauen mit Herzschwäche, Klappenerkrankungen und Rhythmusstörungen besteht, müssen zukünftige Analysen klären. In jedem Fall müssen Frauen ihrer Herzerkrankung entsprechend diagnostisch und therapeutisch so weit versorgt werden, dass ein Ungleichgewicht in der Sterblichkeit nicht auf Versorgungsunterschieden beruht", betont die Deutsche Herzstiftung. Allerdings müssten frauenspezifische Besonderheiten wie hormonelle Unterschiede, Wirkungsunterschiede von Medikamenten aufgrund von Stoffwechselprozessen, unterschiedliche Anatomie der kleinen Herzkranzgefäße und die verminderte Wahrnehmung von Herzinfarkt-Symptomen bei Frauen, besonders im hohen Alter, in diese Analyse einfließen.

Der Deutsche Herzbericht 2016 kann kostenfrei angefordert werden unter http://www.herzstiftung.de/herzbericht oder per Tel. unter 069955128400 . Auch einen Herzinfarkt-Risiko-Selbsttest bietet die Herzstiftung an.

Quelle: Deutsche Herzstiftung www.herzstiftung.de 